\title{
Assessing gender trends in Canadian urology
}

Leandra Stringer ${ }^{1}$; Heather Morris ${ }^{1}$; Ailsa May Li Gan²; Alp Sener ${ }^{1,3,4}$

${ }^{1}$ Division of Urology, Department of Surgery, Schulich School of Medicine \& Dentistry, Western University, London, ON, Canada; ${ }^{2}$ Schulich School of Medicine \& Dentistry, Western University, London, ON, Canada; ${ }^{3}$ Department of Microbiology and Immunology, Schulich School of Medicine \& Dentistry, Western University, London, ON, Canada; ${ }^{4}$ Multi-Organ Transplant Program, London Health Sciences Center, Western University, London, ON, Canada

Cite as: Can Urol Assoc J 2019 April 26; Epub ahead of print. http://dx.doi.org/10.5489/cuaj.5836

Published online April 26, 2019

$* * *$

\section{Abstract}

Introduction: The number of female medical students and physicians entering the workforce is increasing. Despite this trend, some surgical specialties are still considered male-dominant. Urology has a significant male predominance in both residency and independent practice. This male predominance could have an impact on the physician work force, mentorship opportunities for females pursuing surgery, and on medical student attraction to urology as a specialty. Research conducted in the U.S. has shown that although fewer females enter the field of urology, acceptance rates between the two genders are similar. This study aims to identify if a trend towards gender-specific acceptance into urology residency exists within Canada. We also seek to identify if gender trends in acceptance to urology differ from other surgical specialties in Canada and assess the current workforce trends in Canadian urological practice.

Methods: Canadian Residency Matching Services (CARMS) data from the previous 10 years was analyzed. This data was accessed from the CARMS website. ${ }^{1}$ Logistic regression analyses were used to assess if any significant difference exists between the rates of female and male applicant acceptance into urology. These rates were then compared to the rates of female and male acceptance into surgical residency as a whole and to specific surgical specialties, such as general surgery, orthopedics, and otolaryngology.

Results: Within urology applicants, there is no evidence that the success rate over time between males and females differs $(\mathrm{p}=0.47)$. Within surgical residency applicants, there is no evidence that the success rate over time differs between male and female applicants $(\mathrm{p}=0.84)$. In comparing these two rates, there is also no significant difference between rates of acceptance to urology vs. surgery in general for female applicants $(\mathrm{p}=0.45)$. General surgery has a higher growth of females entering into the specialty compared to urology $(\mathrm{p}=0.016)$. Conversely, 
otolaryngology $(\mathrm{p}=0.123)$ and orthopedics $(\mathrm{p}=0.163)$ did not show a significant difference in the rates of female acceptance as compared to males over time. Our small sample size of 451 applicants over the 10-year time span (122 female, 329 male) could represent a limitation, however, we did ensure to analyze a 10-year sample to attempt to get an accurate representation of any trends.

Conclusions: Our data identifies that there is no significant trend toward male acceptance into urology over female applicants. There is no significant difference related to female acceptance specifically into urology or any difference between rates of females accepted into urology as compared to all other surgical subspecialties combined.

\section{Introduction}

The number of women entering into, and practicing medicine has been steadily increasing in Canada. In 1968 only fourteen percent of medical students were women, however in 2016, fifty six percent of medical students were women. Over the course of forty-eight years, the population of women in medical education has quadrupled. ${ }^{2}$ Currently, fifty-four percent of the physician workforce under the age of forty, in Canada, is female. ${ }^{3}$ Although the number of women physicians is increasing, there continues to be fewer women in surgery, and specifically, urology.

US data regarding gender and acceptance into urology has shown that there is a significant difference in the number of male applicants as compared to females per year. ${ }^{1}$ However, there is no significant difference in the mean successful match rate of male vs female residency applicants. In the United States, in terms of growth of the female population in all medical specialties, urology had the largest growth of female residents over a four year period from 2009-2013. ${ }^{4}$

There are certainly innumerable possibilities as to why fewer women are entering into, and thus practicing in the field of urology in Canada and the United States. The purpose of this study is to assess the acceptance trends for female urologists in Canada, and compare these to the acceptance trends for other surgical subspecialties such as general surgery, otolaryngology and orthopedics. We also compare to all surgical subspecialties as a whole. We decided to use general surgery as a main comparator as it is a demanding surgical subspecialty with a similar timeframe for training. In addition, general surgery would also likely present similar difficulties for females considering balancing work and family. Lastly, we assess the current workforce of female urologists in Canada, and seek to discuss any potential biases which may influence students entering training programs. 


\section{Methods}

Canadian Residency Matching Service (CaRMs) match data results from 2007-2017 were utilized. ${ }^{1}$ A retrospective analysis of the number of males and females who listed as their top preference and subsequently matched to urology and to all surgical subspecialties was performed. All first round applicant data was analyzed. The primary outcome of this study was to determine the rate of female and male acceptance to urology and to all surgical specialties for each year of the match. A logistic regression analysis was performed.

An additional retrospective analysis was performed using Canadian Medical Association Physician Census data from 2000-2016 and data from 2018 (2017 excluded based on missing available data). ${ }^{5}$ Using a logistical regression analysis the rates of growth of female population in urology was compared to that of general surgery.

We obtained Canadian workforce data from the Canadian Urological Association which was based upon censor data and membership rosters.

\section{Results}

With respect to rates of admission into urology, there are fewer female applicants than males (Table 2), however there was no evidence that success rates over time differ between males and females $(p=0.47)$. When comparing urology to general surgery, there were no difference in the rates of females being accepted to general surgery as compared to urology $(p=0.45)$. When we compared the rates for admission of females in urology compared to all surgical subspecialties combined there was no significant difference in the rate of acceptance of women over time $(\mathrm{p}=$ 0.45). When we compare the growth of female acceptance in otolaryngology, and orthopedics compared to urology there was no significant difference in the rates of acceptance $(p=0.123$ and $\mathrm{p}=0.163$ respectively).

With respect to practicing physicians, comparison of rates of the growth of female surgeons in general surgery as compared to urology did show a significant difference (Figure 1). The rate of growth of female general surgeons since 2000 increased at a higher rate than female urologists $(\mathrm{p}=0.016)$.

Recent data from practicing physicians in Canada reveals that twenty eight percent of surgeons in Canada are women. ${ }^{5}$ However, only eleven percent of urologists in Canada ${ }^{6}$ and nine percent of urologists in the United States ${ }^{7}$ are female. This trend of fewer female urologists persists into training as well. Twenty-five percent of residents and eighteen percent of fellows currently training in urology in Canada are female (Table 1). Although the proportion of females applying to urology in Canada has increased over the last two decades, ${ }^{8}$ urology continues to have the lowest percentage of females as compared to all other medical specialties in Canada. ${ }^{5}$ Despite an increasing population of women entering into medical practice, there continues to be a low number of women in urology. By age cohort, there are no female urologists greater than sixty-five years of age in practice, whereas one hundred and six men in that age group are practicing urologists in Canada. In the thirty-five to fourty-four year old age cohort there are thirty-three females and one hundred and fifty-six male urologists practicing in Canada. ${ }^{6}$ 


\section{Discussion}

The main purpose of this study was to assess gender trends in urology residency training in Canada and identify if there was any difference in the rates of females being accepted into urology residency programs and to compare these rates to other surgical specialties. Our overarching goal was to try to identify why so few females are pursuing urology as a future career so as to be able to propose solutions for future generations of program directors, national society's and potential applicants.

Our study highlights that should a Canadian female medical student choose to apply, and pursue urology, she does have an equal chance of being accepted to a program, when compared to a male applicant. However, despite this equivalent acceptance rate, there is still a much lower number of practicing female urologists than males.

There are a multitude of possible reasons female residency applicants do not consider urology. Do potential candidates have concerns related to their ability to practice urology and have a family? Are they dissuaded by the high rates of burnout in urology ? ${ }^{9}$ Are the demands of training and work hours undesirable for females? Is it possible that female medical students are not gaining enough exposure to urology during their clerkship year? Potentially female medical students have misperception that urology is a male specific career and thus have less of an interest considering a career in urology. Perhaps mentorship is an issue. With less females currently practicing in urology, female medical students are not as likely to be exposed to successful women urologists and seek their guidance regarding future career choices. There is also a possibility that there may be bias on the side of the programs that accept urology resident candidates. Could residency programs be favouring male applicants over females? In order to open the discussion and shed light on this important topic, we pursued an analysis of current data regarding gender in urology, and more specifically, acceptance trends into Canadian urology residency training programs.

Our study highlights that, similar to US data, there is no real difference in the rates of acceptance of females into urology training programs. ${ }^{4}$ Thus, the lack of female urologists cannot be attributed to bias in the residency application process. We then looked into the rate of growth of females in urology over time. It could be possible that due to previous lower rates of females in medicine, the population simply has not caught up to match the male urology population. Therefore, to assess the rate of growth, we compared the population growth of females in urology to that of general surgery. We felt general surgery would be a fair comparator as it is an equally demanding surgical specialty with a rigorous residency and would likely present similar concerns to female applicants related to work, life and family balance. This comparison identified that the number of females in urology is growing at a slower rate than females in general surgery. This begs the question of why? A study by Kim et al ${ }^{10}$ sought to identify medical student's perspective of urology as a specialty. This study identified factors associated with a positive perception of urology as a future specialty. They found that being a 
male medical student, as opposed to a female, was associated with a positive perception of urology. They also identified that medical students had an overall perception that urology is a male-dominated specialty. ${ }^{10}$ It is possible that males are inherently attracted to the specialty of urology, but it could also be that because medical students see urology as male-dominated, female students do not consider urology as an option. Alternatively, it is certainly possible that since the majority of urologic patients are male, perhaps females are less inclined to pursue a specialty where a large portion of their practice is treating the opposite gender.

We certainly do not propose that there should be an equal number of male and female practicing urologists. However, it is important to ensure that females are adequately represented in the specialty as they not only provide diversity but can also bring surgical expertise. Recent research by Wallis et al has shown that patients treated by female surgeons had a small but statistically significant decrease in thirty day mortality and similar surgical outcomes in terms of length of stay, complications and readmission when compared to male surgeons. ${ }^{11}$ It is very important to ensure that as a whole, urology is successful in recruiting the best candidates, and some of these are likely to be women.

If women are keen to seek out other rigorous specialties such as general surgery, why are they not as likely to pursue urology? We propose that another reason females may not pursue urology could be related to a lack of female urologist mentors. As females consider different specialties they may wish to discuss the lifestyle, work hours, work environment and aspects of the career with someone of the same gender. A study by Mayer et $\mathrm{al}^{12}$ found that only twentythree percent of men in surgical training had a female faculty as their mentor whereas ninety percent of women had a male faculty as their mentor during training. Eighty percent of women felt that female medical students need successful female faculty role models. Observing successful females actively practicing in urology may encourage more medical students to pursue urology and provide guidance of how to balance all of the demands of being a female in a surgical specialty, especially one that is male dominant. Perhaps a lack of female urologist mentors is due to the fact there are so few female urologists employed at academic institutions. One way to address this would be to encourage and foster female academic urologists, to ensure partnerships with women urologists in the community, and host mentorship evenings or guest lectures where surgically inclined medical students can have an opportunity to see and interact with a female urologist.

Baxter et al ${ }^{13}$ assessed Canadian medical students to identify factors contributing to choosing a future specialty. They found males focus on technical challenge, prestige and earning rates whereas females consider residency conditions, potential for part time work and parental leave ability as important aspects of a future specialty. Females were more likely than males to identify a lack of role models and were less likely to pursue surgical electives. These factors could directly contribute to the low numbers of women entering into urology. Urology as a specialty can be seen as demanding, time consuming and potentially difficult to take a parental leave from. Without exposure to many female urologist role models who have set a precedent for taking a parental leave or balancing the demands of family and career, it may be difficult for 
female medical students to envision themselves thriving in the specialty and being able to achieve these goals. A Swiss study assessed medical students' specialty choices and came to similar conclusions as they found that women medical students often want to complete residency quickly to be free to plan a family, seek out specialties with more flexible work hours, and prioritize extra-professional obligations, in addition to work related responsibilities more than males. ${ }^{14}$

The present data captures only a ten-year span of urology applicants. Despite this limitation, we do believe that this is a representative sample for analysis of the gender disparities in urology in the current climate of medical education. Our conclusions are relevant and important for consideration by both training programs and overarching professional urologic societies as we move forward into the future.

Ultimately, there is a great deal of research aiming to identify factors that affect gender and specialty career choice. However, there appears to be a dearth of research into why such a gender disparity exists in urology specifically. With a growing number of female medical students, we need to address the lack of women in urology, identify potential causes and try to address them such that we can ensure we are attracting a diverse population of the best, most qualified applicants into the field. Our study has shown that rates of females and males being accepted to urology are similar in Canada. This helps to rule out bias on the part of the urology programs as a cause for low numbers of females in urology. There is still much research to be done regarding factors influencing women's perspectives on urology and even career trends of females practicing in urology.

\section{Conclusion}

Our data identifies that there is no significant trend toward male acceptance into urology over female applicants. It highlights that if a female Canadian medical student wishes to pursue urology, she will have the same chance of gaining acceptance into a training program as a male Canadian medical student. We also show that there is no significant difference related to women acceptance specifically into urology or any difference between rates of females accepted into urology as compared to all other surgical subspecialties combined. We hope that our study and discussion can highlight potential causes and solutions for the low number of women currently training in, and practicing urology in Canada. 


\section{References}

1. Canadian Resident Matching Services. R-1 data and reports, 2007-2017. Available electronically at: https://www.carms.ca/data-reports/r1-data-reports/. Accessed February 10,2019

2. Association of Canadian Medical Colleges. Canadian medical education statistics. Statistiques relatives à l'enseignement médical au Canada. 2017. Available electronically at: https://afmc.ca/sites/default/files/CMES2017-Complete.pdf. Accessed on October 15, 2018.

3. Canadian Institute for Health Information. Physicians in Canada, 2016: Summary Report. 2017. Available electronically at: https:/www.cihi.ca/en/access-data-reports/. Accessed on October 15, 2018.

4. Halpern JA, Lee UJ, Wolff EM, et al. Women in urology residency, 1978-2013: A critical look at gender representation in our specialty. Urology 2016; 92: 20. Available electronically at: https://doi.org/10.1016/j.urology.2015.12.092. Accessed on October 15, 2018.

5. Canadian Medical Association. Number of physicians by specialty and age, Canada, 2017. CMA Masterfile. 2017. Available electronically at: https://www.cma.ca/En/Pages/physician-historical-data.aspx. Accessed on October 15, 2018.

6. Canadian Medical Association. Urology Profile. CMA Masterfile. 2018. Available electronically at: https://www.cma.ca/Assets/assets-

library/document/en/advocacy/profiles/urology-e.pdf. Accessed November 25, 2018.

7. American Urological Association. The State of Urology Workforce and Practice in the United States 2016. Linthicum, Maryland, U.S.A. 2017. Available electronically at: https://www.auanet.org/research/research-resources/aua-census/census-results. Accessed on October 15, 2018.

8. Anderson $\mathrm{K}$, Tennankore $\mathrm{K}$ and Cox A. Trends in the training of female urology residents in Canada. J. Can. Urol. Assoc 2018; 12: E105. Available electronically at: https://dx.doi.org/10.5489\%2Fcuaj.4697. Accessed on October 15, 2018.

9. Franc-Guimond J, McNeil B, Schlossberg SM, et al. Urologist burnout: Frequency, causes, and potential solutions to an unspoken entity. Can Urol Assoc J 2018;12:137-42. Available electronically at: http://dx.doi.org/10.5489/cuaj.4668. Accessed on February 5, 2019.

10. Kim S, Farrokhyar F and Braga LH. Survey on the perception of urology as a specialty by medical students. Can. Urol. Assoc. J 2016; 10: 349. Available electronically at: https://doi.org/10.5489/cuaj.3621. Accessed on October 15, 2018.

11. Wallis CJD, Bheeshma R, Coburn N, et al. Comparison of postoperative outcomes among patients treated by male and female surgeons: a population based matched cohort study. BMJ 2017;359:4366-76. Available electronically at: https://doi.org/10.1136/bmj.j4366. Accessed on February 4, 2018.

12. Mayer KL, Perez R V. and Ho HS. Factors affecting choice of surgical residency training program. J. Surg. Res 2001; 98: 71. Available electronically at: https://doi.org/10.1006/jsre.2001.6143. Accessed on October 15, 2018.

13. Baxter N, Cohen R and McLeod R. The impact of gender on the choice of surgery as a career. Am. J. Surg 1996; 172: 373. Available electronically at: 
https://doi.org/10.1016/S0002-9610(96)00185-7. Accessed on October 15, 2018.

14. Buddeberg-Fischer B, Klaghofer R, Abel T, et al. The influence of gender and personality traits on the career planning of Swiss medical students. Swiss Med. Wkly 2003; 133: 535. Available electronically at: https://dx.doi.org/10.1186\%2F1472-6963-6137. Accessed on October 15, 2018. 


\section{Figures and Tables}

Fig. 1. Growth rate of the percentage of female surgeons in general surgery vs urology from 2000-2018. The growth rate was significantly higher in general surgery than in urology.

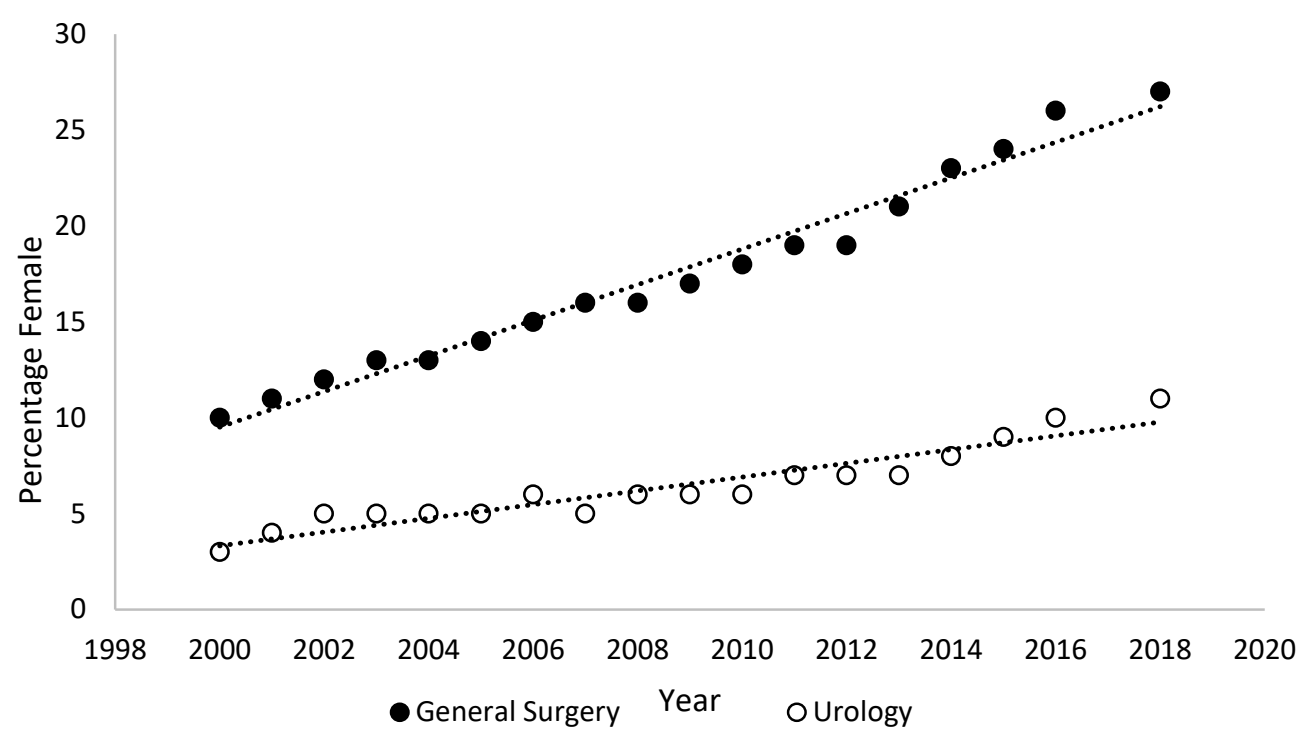

Fig. 2. The rate of acceptance of females vs. males into general surgery and urology residency programs in Canada over an 11-year period (2007-2017). There was no significant difference between rates of females being accepted into urology as compared to general surgery.

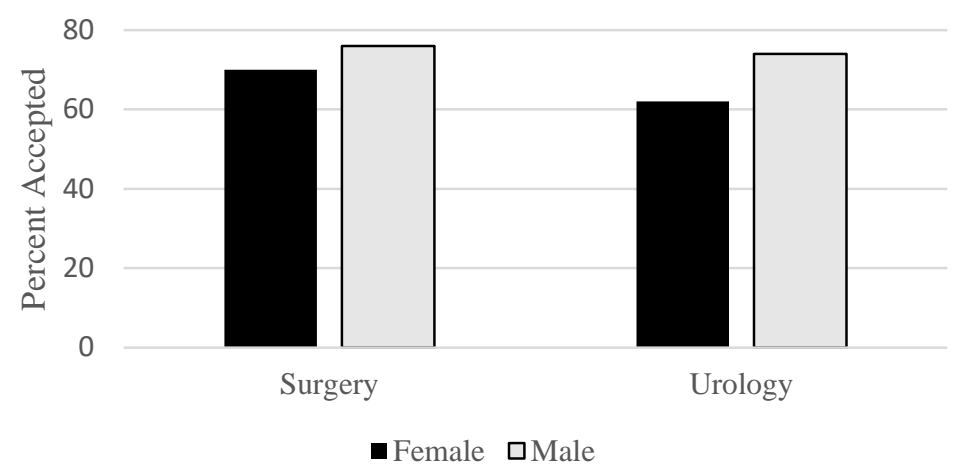




\begin{tabular}{|c|c|c|c|}
\hline & Female & Male & Percent female \\
\hline Residents & 52 & 153 & 25 \\
\hline Fellows & 11 & 50 & 18 \\
\hline Staff & 63 & 526 & 11 \\
\hline
\end{tabular}

\begin{tabular}{|l|c|c|c|c|c|c|}
\hline Table 2. Female vs. male listings of first choice specialty vs. acceptance \\
\hline Year & $\begin{array}{c}\text { Female } \\
\text { first choice }\end{array}$ & $\begin{array}{c}\text { Female } \\
\text { accepted }\end{array}$ & $\begin{array}{c}\text { Proportion } \\
\text { female } \\
\text { accepted }\end{array}$ & $\begin{array}{c}\text { Male first } \\
\text { choice }\end{array}$ & $\begin{array}{c}\text { Male } \\
\text { accepted }\end{array}$ & $\begin{array}{c}\text { Proportion } \\
\text { male accepted }\end{array}$ \\
\hline 2007 & 11 & 7 & 0.64 & 27 & 21 & 0.78 \\
\hline 2008 & 9 & 7 & 0.78 & 30 & 22 & 0.74 \\
\hline 2009 & 7 & 5 & 0.71 & 25 & 23 & 0.92 \\
\hline 2010 & 16 & 8 & 0.50 & 34 & 22 & 0.65 \\
\hline 2011 & 7 & 5 & 0.71 & 35 & 23 & 0.66 \\
\hline 2012 & 7 & 7 & 1.00 & 28 & 22 & 0.79 \\
\hline 2013 & 8 & 4 & 0.50 & 38 & 28 & 0.74 \\
\hline 2014 & 22 & 14 & 0.64 & 21 & 17 & 0.81 \\
\hline 2015 & 5 & 3 & 0.60 & 27 & 23 & 0.85 \\
\hline 2016 & 9 & 7 & 0.78 & 33 & 20 & 0.61 \\
\hline 2017 & 21 & 9 & 0.43 & 31 & 22 & 0.71 \\
\hline
\end{tabular}

